\title{
SOCIO-ECONOMIC DETERMINANTS OF VEGETABLE FARMERS' AWARENESS OF SAFETY MEASURES IN PESTICIDE USE IN JERE LOCAL GOVERNMENT AREA, BORNO STATE, NIGERIA
}

\author{
Tijjani, $H^{*}$, Tijjani, B. A and Audu, A. \\ Department of Agricultural Technology, Ramat Polytechnic Maiduguri, Borno State. \\ *Corresponding e-mail: htijjani@gmail.com
}

\begin{abstract}
This study was carried out to determine the socio-economic factors influencing awareness on pesticide use and safety measures by the vegetable farmers in Jere Local Government Area, Borno State. The specific objectives were to identify the socio-economic characteristics of vegetable farmers, determine the level of awareness on pesticide use and safety practices among vegetable farmers, and determine the factors influencing vegetable farmers' awareness on pesticide use and safety measures. A two-stage sampling technique was employed to select eighty-five vegetable farmers across thirteen wards of the local government. Descriptive statistics and logistic regression were used for the analysis. The study revealed that most of the farmers were between the age of 26 and 35 years (36\%) with the majority having household size of 6 to 10 members (44\%) and farm size of less than 10 acres (61\%). Majority (64\%) of the farmers were aware of pesticide safety use and practices (64\%). Fellow farmers were the major source of information on pesticide safety use and practices (48\%). The major factors that influenced awareness among the farmers were age, household size and farm size. Therefore, it is recommended that farmers' awareness on disposal of pesticide containers, mixing of pesticides should be raised through regular workshops and symposia.
\end{abstract}

\section{Keywords: Awareness, Pesticide, Vegetables, Factors.}




\section{INTRODUCTION}

Vegetable farmers use a wide range of pesticides at different levels to reduce losses from pests and diseases. However, despite the contribution of pesticides to agricultural production, evidences in the last few decades have shown that they could be detrimental to human health and the ecosystem (Tadesse and Asferechew, 2008).

Pesticides are often used for both agricultural and non agricultural purposes by many people without proper understanding of the dangers associated with such chemicals. Similarly, dangers to the environment and health are particularly strong in developing countries where environmental laws tend to be lax and the public is little aware of the potential problems. As a result, farmers use pesticides without full understanding of their impact on human health and the environment (Tjornhorm, et. al.,1986; Ngowi, et. al., 2007).

Exposure to pesticides may have chronic effects on human health and widespread development of resistance on other living organisms such that some insects and weeds become resistant to such chemicals at the prescribed dosage. They could also present danger to farmers, consumers and factory workers, indirectly through inhalation, dermal absorption and ingestion or indirectly through dietary intake of food or water. Consequently, there is an eventual effect on species that eat certain prey or use the affected habitats (Banjo, et. al., 2010). Awareness and skills regarding safe and efficient application of pesticides are not adequate at farmers' level, exposing them to risk of pesticide poisoning (Diwakar, et. al., 2008).

The main objective of this study, therefore, is to assess the socio-economic determinants of vegetable farmers' awareness of safety measures in pesticide use in Jere Local Government Area, Borno State, Nigeria. The specific objectives are to (i) describe the socio-economic characteristics of the vegetable farmers in the study area; (ii) assess the level of awareness of vegetable farmers on pesticide use and safety measures; and (iii) determine factors that influence vegetable farmers' awareness on pesticide use and safety measures.

\section{METHODOLOGY}

\section{Study area}

The study was conducted in Jere Local Government Area of Borno State which was created in 1996 with headquarters at Khaddamari. It is located in the Sudan region of Nigeria's vegetation. It lies between latitude $11^{\prime \prime} 40^{\circ}$ and $12^{\prime} 05^{\circ} \mathrm{N}$ - longitude $13^{\prime \prime} 05^{\circ}$ and $12^{\prime} 20^{\circ} \mathrm{E}$ and covers an area of about 250,000 square kilometers with a total population of about 211,204 people (National 
Population Commission, 2006). Jere Local Government Area is bounded by four local governments, namely Konduga to the north, Nganzai to the South, Mafa to the east and Maiduguri Metropolitan to the west.

The climate of Jere is like that of other areas found within the Sudan region characterized by two seasons, rainy and dry seasons. The rainy season starts from May and lasts till October, while the dry season begins from November - April. The warm temperature of the region range from 30 $40^{\circ} \mathrm{C}$ with peak $40^{\circ} \mathrm{C}$ around March to April. The rainfall of the region ranges from 900 millimeters to 950 millimeters or 30-35 inches animally.

The predominant ethnic groups in the local government are Kanuri, Shuwa, Hausa and Fulani, while crop production and cattle rearing are the predominant occupations of the people. Crops such as millet, guinea corn, rice and beans are the main cash crops of the local government. Similarly, vegetable production is also another major source of income in the study area, mostly practiced under irrigation system and less under rain fed farming. Other economic activities include pesticide trading, fishing and craftsmanship.

\section{Source of data}

Both primary and secondary information were used for the study. The primary data was generated through structured questionnaires administered to randomly selected respondents while the secondary source of information include textbooks, journals, articles, conference proceedings, bulletins, annual reports and other relevant publications.

\section{Sampling technique}

A two-stage sampling technique was used to generate data for the study. In the first stage, six (6) wards were purposefully selected out of the thirteen (13) wards being predominantly vegetable producing areas. In the second stage, 85 vegetable farmers were randomly selected from the six (6) wards earlier selected to generate a sample size of respondents for the study.

\section{Analytical technique}

Both descriptive and inferential statistics were employed for the analyses. The descriptive statistics such as frequency, percentage and ranking were used to achieve objectives I and II while inferential statistics (logistic regression) was used to achieve objective III of the study. 


\section{Logistic regression}

This is estimated using Maximum Likelihood Estimation (MLE), unlike linear regression which uses the Ordinary Least Square (OLS) approach. MLE is an iterative procedure, meaning that it starts with a guess as to the best weight for each predictor variable and then adjusts these coefficients repeatedly until there is no additional improvement in the ability to predict the value of the outcome variable (either 0 or 1 ) for each case.

\section{Empirical model estimation}

The binary logit model for investigating factors that influence probability of farmers' awareness of safety measures in pesticide use was modeled as follows:

$$
\operatorname{Pr}\left\{\text { Aware }_{\mathrm{i}}=1\right\}=\frac{\exp \left\{\beta o+\beta_{\mathrm{i}} x_{\mathrm{i}}\right\}}{1+\exp \left\{\beta o+\beta_{\mathrm{i}} \beta_{\mathrm{i}}\right\}}
$$

where Aware is the state of awareness of ith farmer ( $1=$ aware, $0=$ otherwise); $x$ denotes a vector of farmer's socio-economic characteristics that influence awareness of safety measures in pesticide use; $\beta$ represents the vector of parameters to be estimated. Marginal effects were estimated to measure the effects of changes in any explanatory variable on the predicted probability of awareness of safety measures in pesticide use, ceteris paribus. The marginal effects for continuous variable and dummy-coded variables were computed following Equations 2 and 3 , respectively.

$$
\boldsymbol{\beta} \boldsymbol{m}=\left[\partial\left(\boldsymbol{\beta}_{\mathrm{i}} \boldsymbol{x}_{\mathrm{i}}+\mathcal{E}_{\mathrm{i}}\right) /\left(\partial \beta_{\mathrm{i}} x_{\mathrm{i}}\right)\right] \beta_{\mathrm{i}}
$$

$\beta m=\operatorname{Pr}\left[\right.$ Awaresmpu $\left._{\mathrm{i}}=1\right]-\operatorname{Pr}\left[\right.$ Awaresmpu $\left._{\mathrm{i}}=0\right]$

\section{RESULTS AND DISCUSSION}

\section{Socio-economic characteristics of the vegetable farmers}

Table 1 presents data on socio-economic characteristics of the respondents. The findings revealed that majority (36\%) of the respondents were between the age of 26 and 35 years. About $44 \%$ of the respondents had a household size of six to 10 members. This could be probably due to the polygamous nature of most of the households in the study area, where family labour contributes a lot to farming activities. 
The majority $(61 \%)$ of the respondents had a farm size of less than 10 acres. This could be attributed to the small-scale farming practiced coupled with the use of manual tools in almost all the farming practices pesticide application inclusive. This also affirms the findings of Abbasy (2017) who reported that - $65 \%$ - of the farmers interviewed were typically smallholder farmers having land holdings about one hectare, $35 \%$ above 1.0 ha.

About $50 \%$ of the respondents had between 6 and 10 year experience in vegetable production. Distribution of the respondents by educational level show that majority $(58 \%)$ of the respondents had Islamic education, $18 \%$ had adult education, $12 \%$ secondary education, $8 \%$ primary education and $4 \%$ tertiary education. This implies that those with Islamic education dominate vegetable farming in the study area.

About $36 \%$ of the respondents had an annual income between $\$ 201,000$ and $\$ 300,000$; this is followed by $24 \%$ who had $\$ 101,000$ to $\$ 200,000$ annual income, and $21 \%$ had $\$ 301,000$ to $\$ 400,000$ annual income, while $11 \%$ and $8 \%$ of the respondents had less than $\$ 100,000$ and more than $\$ 401,000$ annual income respectively.

Table 1: Distribution of respondents by socio-economic characteristics

\begin{tabular}{lll}
\hline Variable & Frequency & Percentage \\
\hline Age (years) & 15 & 18 \\
Less than 25 & 31 & 36 \\
$26-35$ & 23 & 27 \\
$36-45$ & 13 & 15 \\
$46-55$ & 03 & 04 \\
More than 55 & & \\
Household size (numbers) & 23 & 27 \\
Less than 5 & 37 & 44 \\
$6-10$ & 15 & 18 \\
$11-15$ & 08 & 09 \\
$16-20$ & 02 & 02 \\
More than 20 & & \\
Farm size (acres) & 52 & 61 \\
Less than 10 & 22 & 26 \\
$11-20$ & 07 & 08 \\
$21-30$ & & \\
\hline
\end{tabular}




\begin{tabular}{lll}
\hline 31 - 40 & 03 & 04 \\
More than 40 & 01 & 01 \\
Farming experience (years) & & \\
Less than 5 & 21 & 25 \\
$6-10$ & 43 & 50 \\
11 - 15 & 11 & 13 \\
16 - 20 & 06 & 07 \\
More than 20 & 04 & 05 \\
Educational level (years) & & \\
Islamic education & 49 & 58 \\
Adult education & 15 & 18 \\
Primary education & 07 & 08 \\
Secondary education & 10 & 12 \\
Tertiary education & 03 & 04 \\
Annual income (\$'000) & & \\
Less than 100 & 09 & 11 \\
101 - 200 & 20 & 24 \\
201 - 300 & 31 & 36 \\
301 - 400 & 18 & 21 \\
More than 400 & 07 & 08 \\
\hline
\end{tabular}

Source: Field Survey, 2017

Awareness of the vegetable farmers on pesticide use and safety measures

Table 2 presents data on awareness of the respondents on the use of pesticide. The majority (64\%) of the farmers were aware of pesticide use. This is in line with the findings of Jeamponk and Thipsaeng (2014) who reported a high level of awareness of chemical pesticide use among farmers in Suan Luang sub-district municipality, Ampawa, Samut Songkram, Thailand. Similarly, Abbasy (2017) found that most of the farmers (88.4 - 96.5\%) have knowledge and awareness towards safety application of pesticides and not use, such as wear glasses to protect eyes, put on leg boots, put on hand gloves, or protect mouth and nose when spraying.

Findings on sources of information about pesticide use practices reveal that many (48\%) of the sampled farmers sourced information from fellow farmers, 33\% depended on pesticide dealers/vendors, $20 \%$ rely upon extension agents, while $15 \%$ got information from friends and relatives and $6 \%$ had NGOs as source of information on pesticide use practices. This corroborates 
the findings of Shetty et. al., (2010) who reported that $40 \%$ of the sampled farmers studied in some districts of India were depending on pesticide dealers for information, $20 \%$ got information from agricultural officers, and the rest of the respondents relied on sources like company representatives $(10 \%)$, progressive farmers $(9 \%)$ and media like radio $(2 \%)$, television ( $9 \%)$ and newspapers $(1 \%)$. "Application techniques" were used as recommended by majority (65\%) of the respondents, followed by "mixtures and doses" which was equally observed as recommended by about $41 \%$ of the respondents. This is in congruence with the findings of Abbasy (2017) who reported that most $(87 \%)$ farmers mixed two pesticides before application. "Disposal of pesticide containers" was observed as recommended by only $11 \%$ of the sampled respondents in the study area. This coincides with the findings of Gayatri and Amarjeet (2016) who reported that majority of the farmers in Chitwan, Nepal disposed pesticide bottles in a nearby water source. Similarly, Oluyede and Festus (2007) reported that the majority (51\%) of the cotton farmers in northern Cote d'ivoire leave the empty pesticide containers in the field after application, while $32 \%$ threw such containers into the bush. By implication, this practice poses a serious threat to the existence of animals in such location and also exhibits health hazards to human beings who may be the end users of such containers.

Table 2: Distribution of respondents by awareness on pesticide use and safety measures

\begin{tabular}{lll}
\hline Variable & Frequency & Percentage \\
\hline Status of awareness on pesticide use practices & & \\
Yes & 54 & 64 \\
No & 31 & 36 \\
Sources of information (if aware) & & \\
Extension agents & 11 & $20^{*}$ \\
Fellow farmers & 26 & $48^{*}$ \\
Pesticide dealers/vendors & 18 & $33^{*}$ \\
NGOs & 03 & $06^{*}$ \\
Friends and relatives & 08 & $15^{*}$ \\
Practices observed as recommended & & \\
Mixtures and doses & 22 & $41^{*}$ \\
Application techniques & 35 & $65^{*}$ \\
Disposal of pesticide containers & 06 & $11^{*}$ \\
\hline
\end{tabular}

Source: Field Survey, 2017

*Multiple Response 


\section{Socio-economic factors influencing vegetable farmers' awareness of pesticide use and safety measures}

Table 3 shows the socio-economic factors influencing awareness of pesticide use practices. A total of six variables were analyzed using logistic regression model, three variables - age, household size and farm size - were found to significantly influence awareness on pesticide use practices among the respondents in the study area.

The findings indicate that age negatively influenced awareness of pesticide use practices. This implies that young farmers are more likely to become aware of pesticide use practices than old ones. This could be attributed to the fact that old farmers are mostly conservative and tend to ignore any innovation apart from the old and traditional way of doing things. This could impede their likelihood of becoming aware on pesticide use practices. However, this is in contrast with the findings of Tjornhom et al., (1996) who reported that as the age of a farmer increases, the probability that the farmer misuses pesticide decreases.

Similarly, the findings also indicate that household size had a negative influence on awareness of pesticide use practices. This negative coefficient implies that as the size of the household increases, the likelihood of such household on awareness decreases. A plausible inference may be that the head of the household may be grappling to make ends meet with every increase in the household size rather than sourcing information on pesticide use practices. Conversely, this is in contrast with the findings of Adeola (2012) who did not establish a significant relationship between household size and farmers' perception of pesticide environmental effect.

Table 3 further shows that there is a positive relationship between awareness and the farm size used for vegetable production by the farmers. This means that the likelihood of awareness increase with increase in size of the respondent's farm and vice versa. As expected, a larger farm size allows one to experiment innovations (such as new practices on the use of pesticides) in order to hedge against the risk of crop failure.

Table 3: Socio-economic factors influencing vegetable farmers' awareness on pesticide use and safety measures

\begin{tabular}{llllll}
\hline Variables & $\begin{array}{l}\text { Estimated } \\
\text { parameters }\end{array}$ & coefficients & $\begin{array}{l}\text { Standard } \\
\text { errors }\end{array}$ & $\mathbf{Z}$ & $\mathbf{p}$ - value \\
\hline Age (years) & $\mathrm{X}_{1}$ & -.1063137 & .0415563 & -2.56 & 0.011 \\
\hline
\end{tabular}




\begin{tabular}{|c|c|c|c|c|c|}
\hline $\begin{array}{l}\text { Household } \\
\text { size } \\
\text { (numbers) }\end{array}$ & $X_{2}$ & -.1541452 & .0671038 & -2.30 & 0.022 \\
\hline $\begin{array}{l}\text { Farm size } \\
\text { (acres) }\end{array}$ & $X_{3}$ & .0439599 & .02537 & 1.73 & 0.083 \\
\hline $\begin{array}{l}\text { Farming } \\
\text { experience } \\
\text { (years) }\end{array}$ & $X_{4}$ & -.0248824 & .0307144 & -0.81 & $0.418 \mathrm{~ns}$ \\
\hline $\begin{array}{l}\text { Educational } \\
\text { level (years) }\end{array}$ & $X_{5}$ & .0123552 & .0547491 & 0.23 & $0.821 \mathrm{~ns}$ \\
\hline $\begin{array}{l}\text { Annual } \\
\text { income (naira) }\end{array}$ & $X_{6}$ & .0003216 & .0001997 & 1.61 & $0.107 \mathrm{~ns}$ \\
\hline \multicolumn{6}{|c|}{ Log likelihood = -31.561278} \\
\hline \multicolumn{6}{|c|}{ Prob $>$ chi $2=0.0000$} \\
\hline Pseudo R2 = 0 . & 4519 & & & & \\
\hline
\end{tabular}

Source: Field Survey, 2017

CONCLUSION AND RECOMMENDATIONS

Based on the findings of the study, it is recommended that:

1. Extension Agents, NGOs and other relevant stakeholders in the agricultural sector should step up to raise farmers' awareness on disposal of pesticide containers, dosage and mixtures of pesticides through regular workshops and symposia.

2. Farmers, particularly those with large household sizes and the aged ones should be sensitized and motivated through the provision of pesticide protective devices with a view to raising their level of awareness on pesticide use and safety measures. 


\section{REFERENCES}

Abbasy, MMS (2017). Farmers' Knowledge, Attitudes and Practices, and their Exposure to Pesticide Residues after Application on the Vegetable and Fruit Crops. Case Study: North of Delta, Egypt. Journal of Analytical and Toxicology. 5(7):

Adeoye, S.O. and Ugalahi, U.B. (2017). Smallholder Food Crop Farmers' Participation in Bank of Agriculture (BOA) Loan Scheme in Ogun State, Nigeria. Agrosearch. 17(2) 51 -- 66.

Banjo, A.D., Aina, S.A., and Rije, A.I. (2010). Farmers' Knowledge and Perception towards Herbicides and Pesticides Usage in Fadama Area of Okun-Owa, Ogun State, Nigeria. African Journal of Basic and Applied Sciences. 2(5 - 6): 188 - 194.

Diwakar, J., Prasai, T., Pant, SR., and Jayana, BL. (2008). Major Pesticides and Fertilizers Used in Nepal. Science World. 6(6): 76 - 80.

Gayatri, K. and Amarjeet, S. (2016). Patterns of Pesticide Use and Associated Factors among the Commercial Farmers of Chitwan, Nepal. Environmental Heath Insights. 10 (1) $1-7$

Jeamponk, P. and Thipsaeng, T. (2014). Farmers' Awareness and Behavior of Chemical Pesticide uses in Suang Luang Sub-District Municipality, Ampawa, Samut Songkram, Thailand. International Journal of Social, Behavioral, Educational, Economic, Business and Industrial Engineering. 8 (7) 2298 - 2301.

Karoonamoorthi, K., Mohammed, M., and Wassie, F. (2012). Knowledge and Practices of Farmers with Reference to Pesticide Management: Implications on Human Health. Archives of Environmental and Occupational Health. 67: 109 - 116.

National Population Commission (2006). National Census Report, National Population Commisssion, Abuja, Nigeria.

Oladipo, F.O., Bolarin, O., Daudu, A.K., Kayode, A.O. and Awoyele, P.O. (2017). Utilization of Soil Conservation Practices Among Root and Tuber Farmers in Oyun Local Government Area of Kwara State, Nigeria. Agrosearch. 17 (2) 99 - 109.

Olajide, B.R. and Aderolu, M.A. (2017). Effects of Trust Fund Model Credit Intervention on Welfare of Farmers' Households in Oyo State. Agrosearch. 17 ( 2) 38 - 50. 
Shetty, P.K., Murugan, M., Hiremath, M.B. and Sreeja, K.G. (2010). Farmers' Education and Perception on Pesticide use and Crop Economies in Indian Agriculture. Journal of Experimental Sciences 1(1) 3 - 8.

Tijani, A.A. (2006). Pesticide Use Practices and Safety Issues: The Case of Cocoa Farmers in Ondo State, Nigeria. Journal of Human Ecology. 19 (3) 183 - 190. 